\title{
Cholesteatoma Masquerading as Fungal Mastioditis
}

\author{
Manzoor Latoo, M.S., Aleena Jallu, M.B., Rafiq Pampori, M.S.
}

Department of ENT, Head \& Neck Surgery, Govt Medical College, Srinagar.

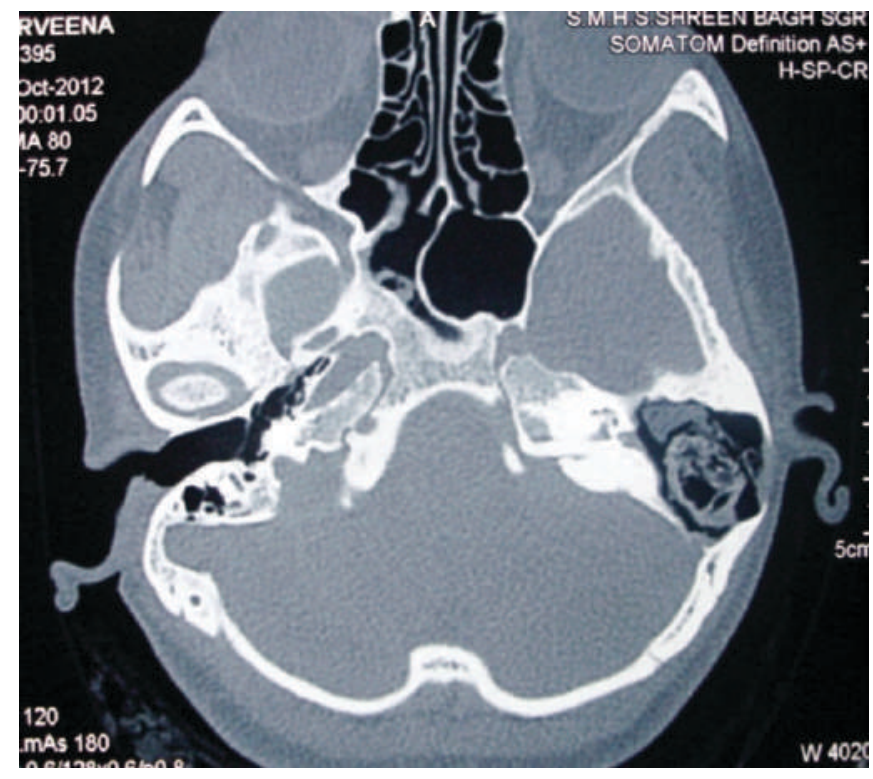

FIGURE 1: Cholesteatoma eroding posterior canal wall, with surrounding air. Mimicking fungal mastoiditis.

A 35 year old female, presented with a history of left side ear discharge that was scanty and foul smelling. Examination revealed subtle facial weakness on the left side and whitish flakes in middle ear and attic (s/o cholesteatoma). Pure tone audiogram revealed moderate conductive hearing loss. HRCT temporal bone was ordered in view of facial weakness which was reported as fungal mastoiditis in view of extensive destruction of mastoid and fallopian canal with radiolucency surrounding the soft tissue mass and also within the soft tissue shadow(Figure $1 \& 2$ ). The patient was operated upon. The posterior canal wall was found eroded, and air going into the mastoid cavity was the reason for the particular radiologic picture(Figure 3). Also the facial canal was found eroded and the facial nerve was lying like a cord covering stapes crurae(Figure 4). Modified radical mastoidectomy with type

\section{Correspondence:}

Dr. Manzoor Latoo

Deptt of ENT, Head and Neck, Government Medical College, Srinagar. E-mail:manzoorlatoo@yahoo.co.in

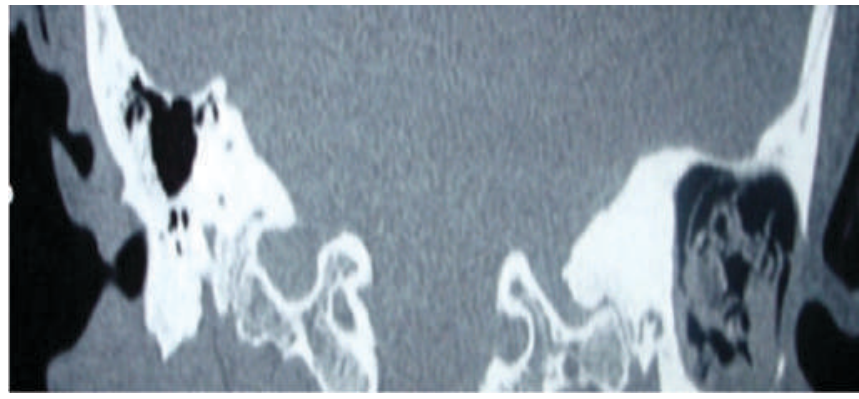

FIGURE 2: Coronal CT showing extensive cholesteatoma with surrounding air due to posterior canal wall erosion and fallopian canal dehiscence

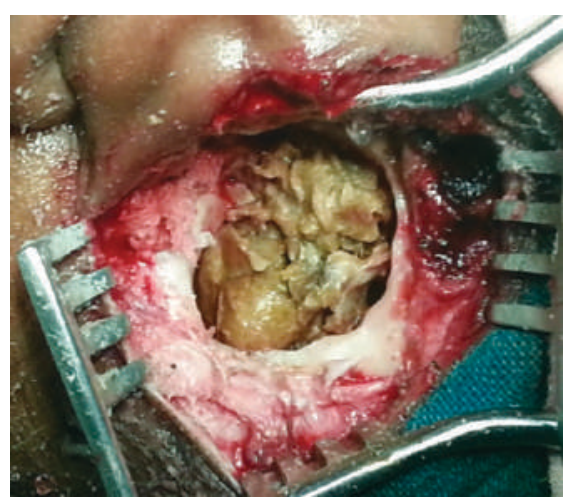

FIGURE 3: Cholesteatoma in mastoid bowl

FIGURE 4: Facial nerve exposed in the middle ear and overlying stapes crurae

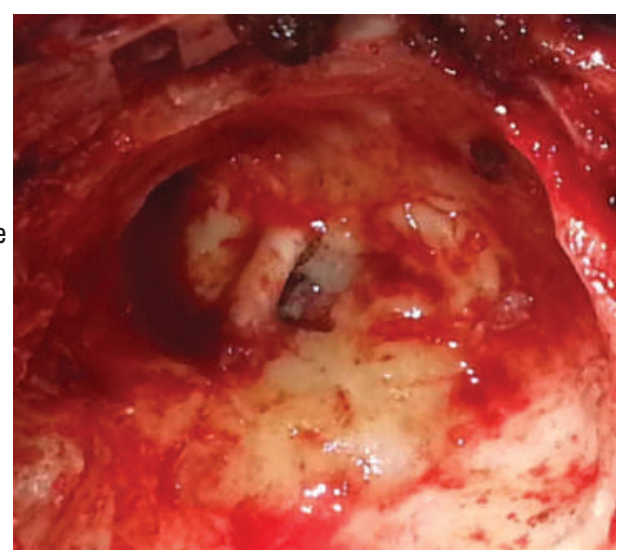

111 tympanoplasty was performed. Facial nerve weakness, which progressed to grade 11 palsy post-operatively (due to edema), recovered after 4 weeks of surgery. 